\title{
Engaging the Diaspora in Response to the 2014 Fogo Volcano Eruption in Cape Verde
}

\author{
Elena Savoia, MD, MPH; Leesa Lin, MSPH; Noah Klein; Alberto Montrond
}

$\mathrm{O}$ n November 23, 2014, a volcanic eruption on the island of Fogo in Cape Verde, of the West Coast of Africa, affected approximately 200 households corresponding to a population of 1498. The eruption continued for 3 months and was the largest eruption, by volume and damage, on the archipelago in over 60 years. ${ }^{1}$ Most damage was caused by lava flows advancing into populated regions, destroying buildings, homes, and roads. As a result, 3 villages were abandoned and hundreds of residents evacuated to camps and schools in nearby areas. There were no injuries or deaths, but the evacuees lost homes and possessions. ${ }^{2}$

This letter seeks to describe an intriguing area of inquiry, the engagement of a diaspora in needs assessment efforts after a disaster in the country of origin to better direct support to the affected populations. This inquiry warrants further study, as the diaspora of any population is a natural and generally committed network that can be tapped into during times of crisis, and because needs assessments are frequently difficult for international organizations to perform in disaster situations.

Between February and April 2015, with the use of a survey designed by our team, volunteers from the Cape Verdean diaspora travelled to Cape Verde and used their personal networks to collect data from the evacuees. Results from the completed surveys, representing $66 \%$ of the evacuated households, revealed a need for housing, safety issues, and health concerns resulting from a lack of sleep, depression, anxiety, and respiratory problems, as well as recommendations for recovery efforts. The results from this needs assessment are consistent with other studies showing how a sense of unity and a desire to rebuild the lost community prevails among evacuees. ${ }^{3}$ Furthermore, risk perception remains low, pressuring a return to the hazardous areas to work the land and sustain families, posing a challenge for future volcano preparedness and mitigation efforts. Detailed results on the survey can be found in a previous publication. ${ }^{4}$

This letter provides an example of how the diaspora can be mobilized in a population's needs assessment after an emergency. When disasters strike, diaspora groups are a crucial lifeline by which to access those in need, as they facilitate the spread of information and supporting the affected communities with volunteer work and remittances. The diaspora has been described as an "invisible first responder" owing to its unstructured and under-recognized role in recovery efforts. ${ }^{5}$ This role should be better integrated with the responses of international organizations because diasporic populations (1) are directly affected by the suffering of family members and friends living in the disaster area; (2) are motivated by feelings of loyalty and solidarity to their country of origin; (3) have an information advantage, because of possessing an understanding of the local language or dialect, as well as the political, economic, cultural, and environmental context; (4) have easy access to local resources; (5) have an economic interest, with remittances and investments in their country of origin; and (6) are trusted and can travel with relative ease.

\section{About the Authors}

Division of Policy Translation and Leadership Development, Harvard T.H. Chan School of Public Health, Boston, Massachusetts.

Correspondence and reprint requests to Elena Savoia, Division of Policy Translation and Leadership Development, Harvard T.H. Chan School of Public Health, Landmark Building 3rd Floor East, Boston, MA 02115 (e-mail: esavoia@hsph.harvard.edu).

\section{Acknowledgments}

We acknowledge partial funding support from the US Centers for Disease Control and Prevention (CDC) cooperative agreement number CDC 1U90TP000417-05 (Preparedness and Emergency Response Learning Center). The content of this report as well as the views and discussions expressed are solely those of the authors and do not necessarily represent the views of any partner organizations, the CDC, or the US Department of Health and Human Services nor does mention of trade names, commercial practices, or organizations imply endorsement by the US Government. We are grateful to FogoFund Inc for their support in the data collection phase.

Published online: January 19, 2016.

\section{REFERENCES}

1. Schmaltz J, Carlowicz M. Eruption at Fogo: image of the day. NASA Earth Observatory website. http://earthobservatory.nasa. 
gov/IOTD/view.php?id=84819. Published December 2, 2014. Accessed October 1, 2015.

2. Smith J. Local Cape Verdeans join to support volcano victims. The Boston Globe. https://www.bostonglobe.com/metro/2014/12/07/local-cape-verdeansjoin-support-volcano-victims/8toZME1G4hBEdhYCugcMKO/story.html. Published December 8, 2014. Accessed July 16, 2015.

3. Tobin GA, Whiteford LM. Community resilience and volcano hazard: the eruption of Tungurahua and evacuation of the faldas in Ecuador. Disasters. 2002;26(1):28-48.
4. Savoia E, Lin L. Engaging the diaspora in assessing population needs after the 2014 Cape Verde volcano eruption. Harvard T.H. Chan School of Public Health website. http://www.hsph.harvard.edu/preparedness/ research_evaluation/evaluation/us/international-activities/population-needsafter-the-2014-cape-verde-volcano-eruption/. Accessed December 18, 2015.

5. UN Web TV. The Role of Diaspora During and After Crisis Situations Side Event to the ECOSOC Humanitarian Affairs Segment Organized by the International Organization for Migration (IOM) [video]. http://webtv.un.org/ watch/the-roleof-diaspora-during-and-after-crisis-situations/3642043201001. Published June 25, 2014. Accessed October 1, 2015.

\title{
Voluntary Medical Support Is Key After Nuclear Disasters
}

\author{
Tomohiro Morita, MD; Masaharu Tsubokura, MD; Tsuyoshi Nemoto, MD; \\ Tomoyoshi Oikawa, MD; Yukio Kanazawa, MD
}

$\mathrm{T}$ he contribution of voluntary support by medical staff is increasingly important during nuclear, biological, and chemical (NBC) disasters. A report highlighted the important role of Médecins Sans Frontières (MSF) during the Ebola outbreak. ${ }^{1}$ We acknowledge the important contributions from voluntary medical providers, which we experienced after the Fukushima Daiichi Nuclear Power Plant accident on March 12, 2011.

Here, we would like to share our experience. The Japanese government established a mandatory evacuation zone for a $20-\mathrm{km}$ radius around the plant. This made our hospital, located $23 \mathrm{~km}$ from the plant, the closest hospital to the plant to continue operating. However, 6 of 13 doctors and 80 of 164 nurses in our hospital had evacuated after the nuclear accident on March 12, 2011. As a result of the decreased staffing, we were not in a position to provide adequate care to hospitalized patients. ${ }^{2}$

Moreover, support from the government was withdrawn as the nuclear situation worsened. Although the government sent 178 medical workers on March 12, the entire team evacuated in 3 days. Similarly, on March 15 the Japan Red Cross Society made the decision not to send any relief teams to a $30-\mathrm{km}$ radius around the nuclear plant.

In contrast to this lack of official support, we received voluntary support. From March 20, 2011, to November 30, 2012, a total of 275 medical staff came on their own volition to provide clinical support to our hospital (Figure 1). They also contributed to post-disaster research by increasing the number of patients participating. Consequently, we were able to investigate the internal radiation dose of $98 \%$ of elementary and junior high school students. ${ }^{3}$ In the end, the voluntary assistance of medical professionals was more influential than support from governmental or nongovernmental institutions, from both clinical and research perspectives.
NBC disasters, natural or manmade, can happen anywhere in the world. We should be aware of the limitations to governmental support. Voluntary support may have the biggest impact on recovery and post-disaster research, as seen in the Fukushima disaster and the Ebola outbreak.

\section{About the Authors}

Soma Central Hospital, Soma City, Fukushima, Japan, (Dr Morita); Division of Social Communication System for Advanced Clinical Research, Institute of Medical Science, The University of Tokyo, Minato-ku, Tokyo, Japan (Drs Morita and Tsubokura); and Minamisoma Municipal General Hospital, Minamisoma City, Fukushima, Japan (Drs Nemoto, Oikawa, and Kanazawa).

Correspondence and reprint requests to Tomohiro Morita, Internal Medicine, Soma Central Hospital, 3-5-18, Okinouchi, Soma City, Fukushima, Japan (e-mail: t.morita526@gmail.com).

Published online: February 1, 2016.

\section{FIGURE 1}

\section{A Picture of Voluntary Medical Staff on March $21,2011$.}

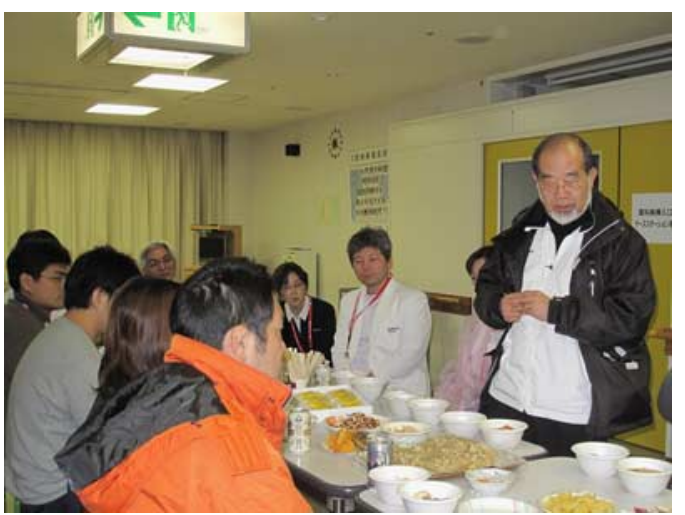

